\title{
Cross-Dimensional Framework:
}

\section{A Way to Integrate Social Context on Personality Assessment ${ }^{1}$}

\author{
Angeline M. Mercado
}

Makati City, Metro Manila, Philippines

mercado.angel.montilla@gmail.com

ORCID ID: https://orcid.org/0000-0003-3965-8582

Preprint DOI: 10.31219/osf.io/f6cnq

1 The Cross-Dimensional Framework was also presented on the 56th Annual Convention Conferences of the Psychological Association of the Philippines, in Davao City, Philippines (September 2019) and at the $3^{\text {rd }}$ Psychological Research Convergence of University of Makati, Makati City, Philippines (November 2019) 


\section{Cross-Dimensional Framework:}

\section{A Way to Integrate Social Context on Personality Assessment}

Despite various advances in methods, personality scale development still tends to focus on traits, leaving social context out of the equation. To address this, CrossDimensional Framework (Cross D) was devised to systematically integrate social context on every item of a personality scale. The framework was used to develop the Cross-Dimensional Conscientiousness Scale (XC). After standardization, XC was administered to 304 Filipino college students along with the Conscientiousness scale items from the International Personality Item Pool Representation of the NEO PI-R (IPIP NEO), and Big Five Inventory (BFI). Statistical analyses were performed to see whether (1) the theoretical assumptions of Cross D are true and if the framework does not compromise the (2) reliability and (3) validity of the test created. The majority of the results support all the theoretical assumptions of Cross D including its effect on reliability and validity of the test, thereby providing evidence of the framework's utility. Besides the novelty of integrating social context on trait measurement, the framework also paves way for the possible quantification of trait's consistent expression across social context.

Keywords: Big Five; personality; test development; social context; social pressure; persona

Running head: Cross-Dimensional Framework 
Personality assessment had gone far from its association with humors in circa $370 \mathrm{BCE}$, to phrenology in 1780s (OpenStax, 2016), then the birth of psychoanalysis in 1895 (Feist \& Feist, 2008). Despite this, personality scales as popularly known today - self-report tests - only rose to popularity towards the early 1900 s.

This shift from client-tailored interviews of psychoanalysis to the pen-and-paper inventories was marked by the creation of Personal Data Sheet (Cohen \& Swerdlik, 2009) which exemplified (1) standardization of trait measurement, and the (2) time-efficient group administration - utility advantages inherent of its format.

To gain these pros, most of the succeeding personality inventories adapted this survey format as well. Nevertheless, the format also comes with the cons of poor adaptability to the diverse and complex nature of personality - a trade-off for giving up the client-tailored probing for a fixed set of generalized statements. This shortcoming tends to dismiss crucial factors which affect personality - such as social context (Bandura, 1997; Rotter, 1982; London \& Oldham, 1977; Johnson \& Chang, 2006; Gardner, Gabriel, \& Lee, 1999). In response to this, Cross-Dimensional Framework (Cross D), was created to incorporate social context on the items of personality scales (Mercado, 2019a).

Although the framework was successfully adapted to develop the CrossDimensional Conscientiousness Scale (or XC read as "Cross C") (Mercado, 2019b), its assumptions are yet to be put to test. To address this need, the paper aimed to evaluate the framework's assumptions: (1) Social factors, namely Social Stipulation and Social Interaction, influences the expression of a trait, and Cross D does not compromise the (2) reliability and the (3) validity of a test constructed based on it. This investigation was expected to aid in establishing the validity of the assumptions which thereby define the utility of the framework. 


\section{Personality Structure and Measurement}

Across paradigms, the idea of personality as a construct has been long focused on its characteristic as a pattern of behavior and thought that occurs consistently across situations; asserting that personality is an internal characteristic rather than a mere reaction to the environment.

This emphasis on the internality of personality is evident in how George Allport, proposed a revision for one of his finest definition of personality - "the dynamic organization within the individual of those psychophysical systems that determine his unique adjustments to his environment" (Allport, Personality: A psychological interpretation, 1937 , p. 48). He later changed the phrase "that determine his unique adjustments to his environment" into "that determine his characteristic behavior and thought" (Allport, Pattern and growth in personality, 1961, p. 28) to make the point that personality is not only reactive but is also proactive and expressive pattern of thought and behavior (Feist \& Feist, 2008, p. 378).

Believing that personality is mostly internal, the search for these universal characteristic patterns of behaviors and thoughts - more commonly called "traits" - had been the trend and theme of the succeeding factor analytical paradigm. With leading proposals such as the Sixteen Personality Factor (Cattell, 1949), triad model of Psychoticism, Extraversion and Neuroticism (Eysenck \& Eysenck, 1975), and FiveFactor Model (McCrae \& Costa, 2003), the community of personality psychology had been on a debate of which and how many factors or traits are necessary and sufficient to cover the whole spectral domain of personality (Feist \& Feist, 2008).

\section{Five-Factor Model}

So far, the most commonly used and widely accepted factorial structure of personality is 
the Five-Factor Model (FFM) by Paul Costa Jr. and Robert McCrae (Feist \& Feist, 2008) owing its scientific reputation from the empirical studies that support its universality and stability of its measurement across culture (Gurven, von Rueden, Massenkoff, Vie, \& Kaplan, 2013; Katigbak, Church, Guanzon-Lapena, Carlota, \& del Pilar, 2002; McCrae, et.al., 2005; Schmitt, et al., 2007; McCrae, 2002). FFM summarizes personality into five traits namely Openness to experience, Conscientiousness, Extraversion, Agreeableness, and Neuroticism which are popularly known as the "Big Five". For this paper, Conscientiousness, one of the Big Five traits was used as the common trait measured by the three personality scales which served as the research instruments.

\section{Influence of Social Context with Personality}

While personality tests continuously grow in number, most only factor in traits. This is despite the prevailing notions that personality is affected by social context as put forward by the Triadic Reciprocal Causation of Albert Bandura, and by the Cognitive Affective Personality Theory of Walter Mischel, and Yuichi Shoda (Feist \& Feist, 2008).

This notion was also supported by researches under various social setting including industries with shared incentive (London \& Oldham, 1977), corporate community with individual workloads (Johnson \& Chang, 2006), and typical daily interaction of students from collectivist and individualist cultures (Gardner, Gabriel, \& Lee, 1999) which found changes in behavior depending on its social context and perceived consequences.

At the time of writing, only few related studies regarding the use of social situation in personality assessment were found and none of them directly address the purpose of Cross D - to categorized social situations and use that category as settings where expression of a trait may vary. The works of Ziegler, Horstmann, and Ziegler (2019) and Rauthmann, et al. (2014) identified factors that measures the characteristics of a situation 
itself, rather than the personality traits across situations. In fact, later part of these studies also found discriminating correlations between the situation factors and the Big Five, a property that Cross D aims to avoid as its aims for universal application across personality traits. Another approach on quantifying personality traits is through situational judgement (Mussel, Gatzka, \& Hewig, 2018) but this approach does not use a taxonomy of situation and did not adapt Likert format.

\section{Cross-Dimensional Framework}

To fill in this gap, Cross D proposed a way to integrate social context on the assessment of personality by sampling behavioral manifestations of traits across social settings. First, the framework identified the four Social Dimensions wherein the behaviors are assumed to vary due to social context. Next, it adds this layer of Social Dimension to the existing structure of trait targeted to be quantified. In doing so, it dissects the trait into contextsensitive units called Cross-Dimensions.

Besides the actual increase in the number of subscales, it also makes item writing more specific. Thus, the stems with Cross D application ask more specific and measurable behaviors (e.g. "I fix my bed right after I wake up." from XC), in contrast with the traditionally all-encompassing stems (e.g. "I like order." from IPIP NEO).

\section{The Structure of Cross D}

At present, the Cross D is composed of four hierarchical Social Dimensions that was anchored from Kapwa and Pakikipagkapwa of Enriquez (1978a; 1997), but instead of treating the two categories of Kapwa - Ibang-tao (outsider) and Hindi-ibang-tao (oneof-us) - as a dichotomy, the Cross D sees it as a continuum through the spectrum of Pakikipagkapwa or social interaction. 
As shown in Table 1, Cross D, restructured the concept of Kapwa by dividing each of its categories into two, and, at the same time, narrowing down the eight (8) levels of Pakikipagkapwa, into four Social Dimensions (Mercado, 2019a). This was done by investigating the factor that differentiates the two types of Kapwa (which was called Social Stipulation) and naming another factor that can further divide the levels of Pakikipagkapwa into two (which is Social Interaction). The presence or absence of these two distinguishing factors defined the four Social Dimensions.

Social Stipulation (SS). The primary role of Social Stipulation is to separate reactive behavior from proactive behavior. In a nutshell, behaviors that spring solely due to Social Stipulation is reactive, while behaviors that were done without the influence of Social Stipulation are proactive in nature.

Thus, Social Stipulation can be defined as an external demand of a social setting or consequence inherent of a certain behavior that pressures a person to act accordingly. Examples of this are monetary reward, career advancement, and social status. Internal reinforcements such as self-improvement, serving the common welfare, or selfexpression do not count as Social Stipulation as they are proactive behaviors rather than reactive (Allport, 1961).

Within the framework, Social Stipulation exists in two Social Dimensions, namely: Individual and Professional, and absent on the other two: Personal and Relational. In Individual Dimension, the Social Stipulation is marked by the consequence of one's action to self, while in Professional Dimension, it is apparent with an action's effect towards self and others. The difference in Social Stipulation between Individual and Professional Dimensions lies in the presence or absence of another factor, Social Interaction. 


\section{Table 1.}

Comparison of Social Dimension to Levels of Kapwa and Pakikipagkapwa

\begin{tabular}{|c|c|c|c|c|c|c|}
\hline \multirow{2}{*}{$\begin{array}{l}\text { Social } \\
\text { Dimension }^{a}\end{array}$} & \multicolumn{2}{|c|}{ Social Factors ${ }^{\text {a }}$} & \multirow[t]{2}{*}{ Kapwa $^{\text {b }}$} & \multirow[t]{2}{*}{ Pakikipagkapwa $^{\mathrm{c}}$} & \multirow{2}{*}{$\begin{array}{l}\text { Language of } \\
\text { Interpersonal } \\
\text { Relationship }^{\mathrm{d}}\end{array}$} & \multirow{2}{*}{$\begin{array}{l}\text { Cultural } \\
\text { Attributes }\end{array}$} \\
\hline & $\begin{array}{l}\text { Social } \\
\text { Stipulation }\end{array}$ & $\begin{array}{l}\text { Social } \\
\text { Interaction }\end{array}$ & & & & \\
\hline \multirow{3}{*}{ Professional } & \multirow{3}{*}{ Present } & \multirow{3}{*}{ Present } & \multirow{3}{*}{ Ibang-tao } & $\begin{array}{l}\text { Pakikitungo } \\
\text { (civility with) }\end{array}$ & Level of amenities & \multirow{3}{*}{$\begin{array}{l}\text { Vertical } \\
\text { Collectivism }\end{array}$} \\
\hline & & & & $\begin{array}{l}\text { Pakikisalamuha } \\
\text { (interaction with) }\end{array}$ & & \\
\hline & & & & $\begin{array}{l}\text { Pakikilahok } \\
\text { (participating with) }\end{array}$ & - & \\
\hline \multirow{2}{*}{ Individual } & \multirow{2}{*}{ Present } & \multirow{2}{*}{ Absent } & \multirow{2}{*}{ Ibang-tao } & $\begin{array}{l}\text { Pakikibagay } \\
\text { (in-conformity with) }\end{array}$ & Level of conforming & \multirow{2}{*}{$\begin{array}{l}\text { Vertical } \\
\text { Individualism }\end{array}$} \\
\hline & & & & $\begin{array}{l}\text { Pakikisama } \\
\text { (being along with) }\end{array}$ & Level of adjusting & \\
\hline Relational & Absent & Present & $\begin{array}{l}\text { Hindi- } \\
\text { ibang-tao }\end{array}$ & $\begin{array}{l}\text { Pakikipagpalagayang-loob } \\
\text { (understanding) }\end{array}$ & Level of mutual trust & $\begin{array}{l}\text { Horizontal } \\
\text { Collectivism }\end{array}$ \\
\hline \multirow{2}{*}{ Personal } & \multirow{2}{*}{ Absent } & \multirow{2}{*}{ Absent } & \multirow{2}{*}{$\begin{array}{l}\text { Hindi- } \\
\text { ibang-tao }\end{array}$} & $\begin{array}{l}\text { Pakikisangkot } \\
\text { (getting involved) }\end{array}$ & -------- & \multirow{2}{*}{$\begin{array}{l}\text { Horizontal } \\
\text { Individualism }\end{array}$} \\
\hline & & & & $\begin{array}{l}\text { Pakikiisa } \\
\text { (being one with) }\end{array}$ & Level of full trust & \\
\hline
\end{tabular}


Social Interaction (SI). The second factor that defines the Social Dimensions is Social Interaction. It refers to the necessary cooperation, collaboration, or communication with others as required by the nature of the behavior, or due to the inherent impact of the behavior on others. Social Interaction also exists once another person was set as the object or receiver of the behavior, even if there is no cooperation, collaboration, or verbal communication required - such as in the case of Relational Dimension.

Social Interaction is present in two Social Dimensions, namely: Professional and Relational, and absent on the other two: Personal and Individual. In Professional Dimension, Social Interaction exists as a reaction to external demand such as deadline, standard of quality, or inevitability of teamwork; as opposed to Relational Dimension, where Social Interaction is proactive or internally motivated. The difference between the two lies in the presence or absence of the first factor, Social Stipulation. Social Dimensions was also matched with related concepts from existing related literature (Triandis \& Gelfand, 1998; Santiago, 1976) for additional context.

\section{Assumptions of Cross D}

Despite literatures that find differences in behavior under varied situational context (London \& Oldham, 1977; Johnson \& Chang, 2006; Gardner, Gabriel, \& Lee, 1999), none of these explicitly supported the postulates of the current framework - that social context affects the way personality traits manifest. Being new and untested, the Cross D lacks backup research to assess its claims and benefits. As a response, this paper aims to evaluate the utility of Cross D by testing its assumptions specifically:

(1) Social context influences the expression of a trait thus:

(a) Role difference exist.

(b) Social Stipulation influences behavior.

(c) Social Interaction influences behavior.

(2) Cross-Dimensional framework does not compromise the reliability of the test. 
(3) Cross-Dimensional framework does not compromise the validity of the test.

\section{Methodology}

To answer these inquiries, Cross D was used to develop Cross-Dimensional Conscientiousness Scale (Mercado, 2019b), a personality inventory that measures Conscientiousness as defined in Five-Factor Model. The newly developed inventory was administered to college students from a Philippine city university along with IPIP NEO, and Big Five Inventory. Data gathered from this was interpreted and analyzed in line with the theoretical basis of Cross D.

\section{Data Gathering}

A total of 304 respondents, were gathered from February 2018 to February 2019 through convenient sampling. The majority of them are Filipino college students at a city university in the Philippines with typical ages ranging from 18 to $22^{2}$.

They were asked to take the XC (Mercado, 2019b) and the Conscientiousness scales of IPIP NEO (International Personality Item Pool, 2019), and BFI (John, Naumann, \& Soto, 2008) within the same day in either online or pen-and-paper format. All scores and responses from the tests were matched and tallied unless a criterion in their respective test manual (e.g. questionable test-taking time) suggests that the result is likely to be invalid.

\section{Instruments}

This study used a total of three personality tests namely Cross-Dimensional

\footnotetext{
${ }^{2}$ Demographic information such as age and gender were made optional to assure anonymity during small group test administration.
} 
Conscientiousness Scale (or XC), International Personality Item Pool (or IPIP NEO), and Big Five Inventory (or BFI). Each of these will be introduced alongside their psychometric properties in the succeeding sections.

The first one, $\mathrm{XC}$, served as the experimental scale where the framework was used. On the other hand, the Conscientiousness scales of IPIP NEO and BFI served as the control scales or the baseline tests that do not use Cross D. Comparisons on their psychometric properties (based on responses from similar respondents) were done so that the relative impact of using the framework can be evaluated.

\section{Cross-Dimensional Conscientiousness Scale (XC)}

$\mathrm{XC}$ is a scale for Conscientiousness that used Cross D to factor in social context on the expression of the said trait. It has internal reliability of $0.96(n=415)$ as piloted on Filipino college students (Mercado, 2019b). The test works under the assumption that social context is not a trait to be measured in itself, but is instead, a factor to be considered for the expression of the traits (Mercado, 2019a).

The assumption was materialized by intentionally aligning the Social Dimensions of Cross D - Personal, Individual, Professional, and Relational - as settings on where the four trait components of Conscientiousness - Aptitude, Orderliness, Commitment, and Deliberation - are expressed as behavior. Thus, each item has a designated Social Dimension and is also categorized under a Trait Component. As a result, the system created a four-by-four matrix of 16 CrossDimensions on where each item falls under (see Table 2).

From this test, a set of 25 scores per examinee (composed of 4 Trait Components, 4 Social Dimensions, 16 Cross-Dimensions, and one overall score for 
Conscientiousness) was gathered for the study. The association of the said scores was summarized on the table below:

\section{Table 2.}

The Interaction of Social Dimensions, Trait Components and Cross-Dimensions

\begin{tabular}{|c|c|c|c|c|}
\hline $\begin{array}{l}\text { Trait Component } \\
\text { Social Dimension }\end{array}$ & Aptitude ${ }^{b}$ & Orderliness ${ }^{b}$ & Commitment $^{\mathrm{b}}$ & Deliberation $^{b}$ \\
\hline $\begin{array}{l}\text { Personal } \\
\text { (Conscientiousness) }^{\mathrm{a}}\end{array}$ & $\begin{array}{l}\text { Personal } \\
\text { Aptitude }^{c}\end{array}$ & $\begin{array}{l}\text { Personal } \\
\text { Orderliness }^{c}\end{array}$ & $\begin{array}{l}\text { Personal } \\
\text { Commitment }^{c}\end{array}$ & $\begin{array}{l}\text { Personal } \\
\text { Deliberation }^{\mathrm{c}}\end{array}$ \\
\hline $\begin{array}{l}\text { Individual } \\
{\text { (Conscientiousness })^{a}}^{a}\end{array}$ & $\begin{array}{l}\text { Individual } \\
\text { Aptitude }^{c}\end{array}$ & $\begin{array}{l}\text { Individual } \\
\text { Orderliness }\end{array}$ & $\begin{array}{l}\text { Individual } \\
\text { Commitment }^{c}\end{array}$ & $\begin{array}{l}\text { Individual } \\
\text { Deliberation }^{\mathrm{c}}\end{array}$ \\
\hline $\begin{array}{l}\text { Professional } \\
\left(_{\text {Conscientiousness })^{a}}\right.\end{array}$ & $\begin{array}{l}\text { Professional } \\
\text { Aptitude }^{c}\end{array}$ & $\begin{array}{l}\text { Professional } \\
\text { Orderliness }^{c}\end{array}$ & $\begin{array}{l}\text { Professional } \\
\text { Commitment }^{c}\end{array}$ & $\begin{array}{l}\text { Professional } \\
\text { Deliberation }^{\mathrm{c}}\end{array}$ \\
\hline $\begin{array}{l}\text { Relational } \\
\text { (Conscientiousness) }^{a}\end{array}$ & $\begin{array}{l}\text { Relational } \\
\text { Aptitude }^{c}\end{array}$ & $\begin{array}{l}\text { Relational } \\
\text { Orderliness }^{c}\end{array}$ & $\begin{array}{l}\text { Relational } \\
\text { Commitment }^{c}\end{array}$ & $\begin{array}{l}\text { Relational } \\
\text { Deliberation }^{\mathrm{c}}\end{array}$ \\
\hline
\end{tabular}

${ }^{\mathrm{a}}$ Social Dimension, ${ }^{\mathrm{b}}$ Trait Component/sub-trait, ${ }^{\mathrm{c}}$ Cross-Dimension, ${ }^{\mathrm{d}}$ General score/trait

In this paper, the term Social Scales was used to refer to the four Social Dimensions and the 16 Cross-Dimensions since they are the subscales that directly consider the social factors. In the same manner, the term Trait Scales was used to collectively refer to four Trait Components (or the sub-traits) and Conscientiousness (which is the trait or the general score) being the subscales that focus on the theoretical structures of the trait itself (see Figure 1). Despite the perspective taken by the Trait Scales, it must still be kept in mind that they are still modified by the framework through their social context-specific items. 


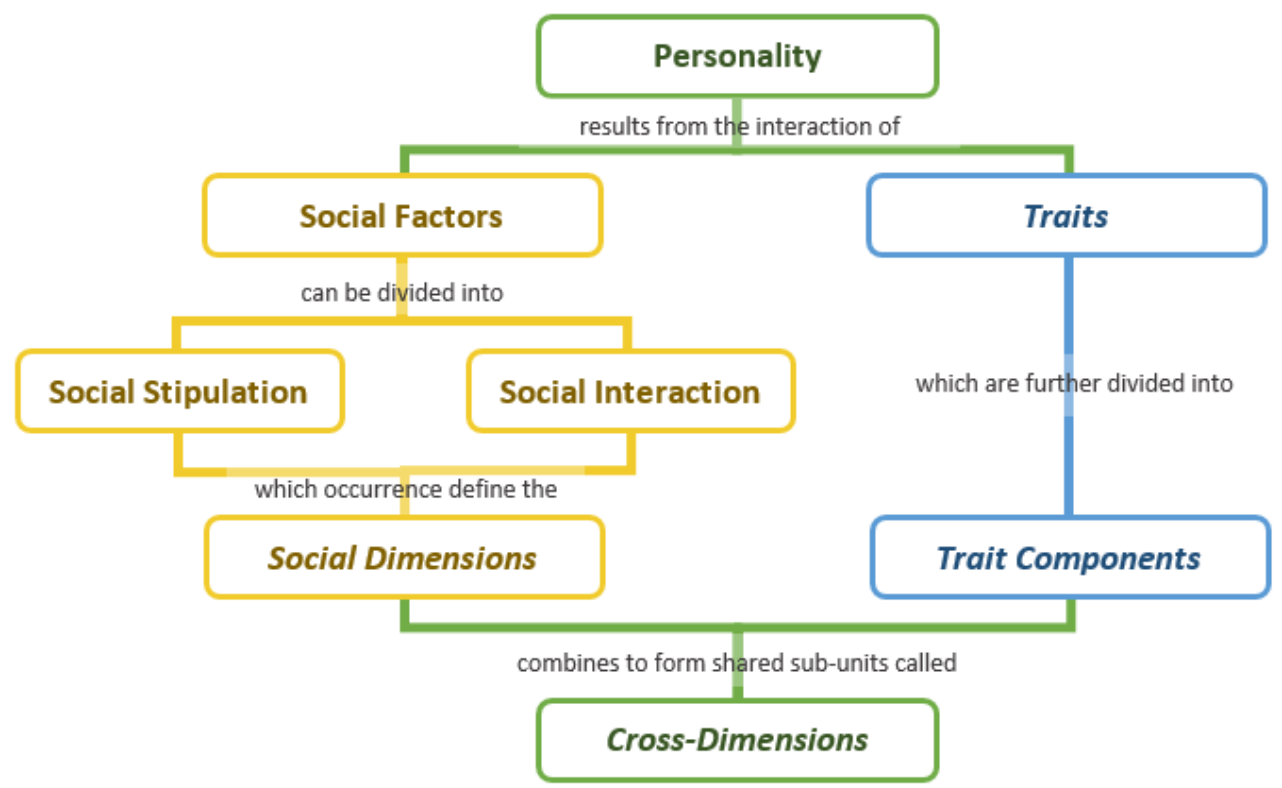

Figure 1. Structure of Cross-Dimensional Framework as integrated on a personality test

Scores from each of the 25 subscales presented were recorded as raw scores. Responses per item itself were also gathered (with negatively keyed item reverse scored) and used as the database for examining the reliability measures and validity correlations.

\section{International Personality Item Pool Representation of the NEO PI-R (IPIP NEO)}

IPIP NEO is a 50-item Big-5 inventory from the International Personality Item Pool. Each trait in the Five-Factor Model has 10 items that use 5-point Likert scale. Based on a study with 811 Greek adults, representative of their population, the test has an internal reliability of 0.875 and acceptable concurrent validity values for the Conscientiousness scale (Ypofanti, et al., 2015).

\section{Big Five Inventory (BFI)}

Similar to IPIP NEO, the BFI also measures all five traits from the Five-Factor Model (John \& Srivastava, 1999). It has 44 items that come with a 5-point Likert 
scale; nine of which measures Conscientiousness. The test was reported to have good internal reliability at 0.89 upon running on 343 Malaysian nurses (Hee, 2014).

While IPIP NEO and BFI measure all five traits in the Five-Factor Model, only the items dedicated to Conscientiousness were used for the interest of the study. This particular trait was chosen to match the scope of $\mathrm{XC}$, and thus serve as a controlled variable. The tests themselves, the IPIP NEO and BFI, served as the control setups where Cross D was not applied.

\section{Organization and Analysis of the Data}

Presentation of analysis can be divided into three parts: (1) gathering evidence of the interaction between social context and the expression of a trait, (2) examining the relative effect of adding Social Dimension on test reliability, and (3) examining the relative effect of adding Social Dimension on test validity. All of these parts document, test, and quantify the validity of the frameworks' assumptions and framework's relative utility in comparison with the current practice and standards.

For within-test comparison, Trait Scales, which are more trait-focused, were used as the controlled while Social Scales served as the experimental. As for the between-tests comparison, IPIP NEO and BFI served as the baseline, being the scales developed with traditional non-Cross D process. Cutoff values were also collected from literature to serve as standards.

The common trait measured by the tests, Conscientiousness, was held constant throughout the process and was not evaluated on its own. Rather, the paper was focused on how Cross D affects the quality of a personality scale.

\section{Part 1: Social context influences the expression of a trait.}

The first part of the analysis is a search for evidence if social context influences the 
expression of a trait. This assumption can be divided into three premises: (1) Role difference exists, (2) Social Stipulation influences behavior, and (3) Social Interaction influences behavior.

Testing these premises was conducted on two levels. The first is on the trait level, through the broader four Social Dimensions, while the second is on sub-trait level, through the more specific 16 Cross-Dimensions.

\section{First Premise: Role difference exists.}

Role difference was defined in this paper as the divergence of a person's behavior across social circumstances due to the interaction of personality and social factors. To examine if role difference exists, the scores on scales measuring a common construct (e.g. Aptitude) but across Social Dimensions (e.g. Personal Aptitude, Individual Aptitude, Professional Aptitude, and Relational Aptitude.) were compared using test of difference. Significant differences theoretically prove that social context affects the expression of personality traits.

Role Difference on Social Dimensions. The presence of role difference was tested using Friedman's Test across the four Social Dimensions with Wilcoxon Signed-rank Test paired with Bonferroni correction as post hoc. Significant differences across Social Dimensions prove the influence of social context on the expression of a trait, and consequently, the existence of role difference across social settings on trait level.

Role Difference on Cross-Dimensions. For the sub-trait level, Friedman test was conducted on four Cross-Dimensions that share the same Trait Component. After which, Wilcoxon Signed-rank Test with Bonferroni correction served as post hoc. Thus, the method required four Friedman tests, one for each Trait Component, and a 
set of Wilcoxon Signed-rank Tests as post hoc for every significant Friedman test result. Differences from these tests consequently shows evidence of role difference on sub-trait level.

Since social context is defined by the presence or absence of Social Stipulation and Social Interaction (as summarized in Table 1), empirical evidences of their existence and influence should also be evaluated; separately as the second and third premises.

\section{Second Premise: Social Stipulation influences behavior.}

To test whether SS influences behavior, test of difference was conducted between Social Dimensions with opposing occurrence of SS but has the same SI occurrence. Thus, Wilcoxon Signed-rank Test was conducted between scores in Personal Conscientiousness and Individual Conscientiousness (both of which lacks SI), and between Relational Conscientiousness and Professional Conscientiousness (both of which has SI). The first subscale for each pair is characterized by the absence of SS, while the second is characterized by its presence.

To quantify the stability of its influence, correlations between Social Dimensions with similar occurrence of SS were gathered. For this, Spearman rho correlation was performed between Personal Conscientiousness and Relational Conscientiousness (since both lack SS), and between Individual Conscientiousness and Professional Conscientiousness (since both have SS).

Parallel tests were conducted for the sub-trait level by using analogous CrossDimensions of each Trait Components instead of the broader Social Dimensions.

\section{Third Premise: Social Interaction influences behavior.}

Likewise, to test if SI influences behavior, Wilcoxon Signed-rank Test was conducted between scores in Personal Conscientiousness and Relational Conscientiousness 
(both of which lacks SS), and between Individual Conscientiousness and Professional Conscientiousness (both of which has SS). For each pair mentioned, the former is characterized by the absence of SI, while the latter is characterized by its presence.

To test the stability of Social Interaction's influence, correlation of Social Dimensions that have similar occurrence of SI were gathered. For this purpose, Spearman rho correlation was performed between Personal Conscientiousness and Individual Conscientiousness (since both lack SI), and between Professional Conscientiousness and Relational Conscientiousness (since both have SI).

For the sub-trait level, similar tests were conducted with corresponding CrossDimensions of each Trait Components instead of the broader Social Dimensions.

Results supporting the first part consequently prove that social factors exist (first premise) and social context (as defined by SI and SS) affects behavior (second and third premise). This also establishes the validity of the social factors as constructs in line with the criteria of Borsboom, Mellenbergh, \& van Heerden (2004) and thus, supports the conceptual foundation of Cross D as applied on a trait scale.

\section{Part 2: Cross-Dimensional framework does not compromise the reliability of the test.}

As a framework for psychometric tests, Cross D should also prove that it can help on improving reliability, or at the very least, does not compromise it. As such, its impact on internal reliability was tested by conducting (1) within-test, (2) betweentests, and (3) against-the-standard comparisons. Average proportional distance (APD) was used as the measure for the purpose since this measure is not affected by the number of items (Sturman, Cribbie, \& Flett, 2009). In APD, lower values reflect better reliability. 
To see whether the framework improved the reliability of the test, within-test, and between-tests comparisons were conducted. For the former, the APD values of each Social Scale were compared with that of Trait scales. For the later, APD values of $\mathrm{XC}$ scales were compared to Conscientiousness scales from IPIP NEO and BFI.

Judging whether the framework improves the internal reliability of a test was based on the percentage of the times when the Social Scales (for within-test comparison), and the $\mathrm{XC}$ scales (for between-tests comparison) received favorable results (lower APD). A percentage greater than 50\% was considered as a sign of better reliability, while $60 \%$ and above is set as the threshold for significant improvement.

To know whether the application of Cross D framework compromised the reliability of the test created or not, against-the-standard comparison was performed. Cutoffs for average proportional distance were set at $.30, .25$, and .20 for average, very good, and excellent consistency, respectively (Sturman, Cribbie, \& Flett, 2009). Any value higher than .30 reflects low reliability and was interpreted as a compromise on reliability.

\section{Part 3: Cross-Dimensional framework improves the validity of the test.}

Since the framework proposed an additional aspect to measure - social factors, its effect on validity is also of concern. To tell whether the Cross D improved the test's validity, (1) within-test and (2) between-tests comparison was conducted. To see whether it did not compromise validity, (3) against-the-standard item validity was also done.

\section{Within-test Comparison of Concurrent Validity}

For within-test comparison, the concurrent validity (Cronbach \& Meehl, 1955, p. 
282) of Social Scales was compared to that of Trait Scales. Correlations were anchored to IPIP NEO and BFI Conscientiousness scale scores as the external criterion. While a stronger positive correlation necessarily equates to better concurrent validity, the differences between values were still evaluated for statistical significance using the work of Lenhard and Lenhard (2014).

For between and against-the-standard comparison, the item validity values were gathered and treated as an extension of construct validity (Campbell \& Fiske, 1959). In this measure, higher correlation means better fit of the item to the construct it is supposed to measure, thereby providing a value that is comparable to factor loading of construct validity (Clark \& Watson, 1995, p. 314; Campbell \& Fiske, 1959).

Item validity (Parry \& Crossley, 1950), was quantified using the item-total correlation for the subscale. To account for the rise in correlation due to the inclusion of item-score, the total subscale scores were operationalized as the respective scale raw score, less the score from the item of concern (Howard \& Forehand, 1962, p. 731)

\section{Between-tests Comparison of Average Item Validity}

In between-tests comparison, the mean item validity of each $\mathrm{XC}$ scale was gathered and compared to parallel values of IPIP NEO and BFI Conscientiousness scales. Since there are only two baselines, the XC scales need to have better item validity at least once in these comparisons to say that the framework aided on validity.

\section{Against-the-standard Comparison of Item Validity}

To see whether the framework compromised the test's validity, item validity values were evaluated based on the standards used by various literatures (Wolfinbarger \& Gilly, 2003; Hinkin, 1995; Nurosis 1994; Cristobal, Flavián, \& Guina, 2007). Cutoffs 
were set at .30, .40, and .50 for average, good, and excellent item validity respectively. Values lower than .29 were considered as low.

\section{Results}

This section summarizes the findings from the analysis. The first part examines the assumptions of Cross D, followed by the observation of its effect on (2) reliability and (3) validity. Each of these parts were further divided into more specific topics as represented by an assumption (for Part 1) or a particular point of comparison (for Part 2 and Part 3).

\section{Part 1: Social context influences the expression of trait.}

This part focuses on the evidences of social context and its influence on the expression of a trait as shown by the scores. This was further divided into three subsections, each summarizing the evaluation of a premise on both trait and sub-trait level.

\section{First Premise: Role difference exist.}

To see if role difference exists and affects behavior, Social Dimensions (for trait level) or Cross-Dimensions (for sub-trait level) was tested for difference with Friedman test and Wilcoxon Signed-rank tests with Bonferroni correction as post hoc.

As shown on Appendix A.1, there are significant differences $(\mathrm{p}<.001)$ between Social Dimensions and Cross-Dimensions with moderate effect ranging from .243 to .490 . Upon performing post hoc tests (see Appendix A.2), it was found that at trait level, all six paired comparison have significant differences $(p<.001)$, while for the sub-trait level, 21 out of 24 paired comparisons were also significant ( $p$ $<.001)$ even with the Bonferroni correction's LDS p-value of .008. In general, these 
findings support the premise that role difference exist, both on trait and sub-trait level.

\section{Second Premise: Social Stipulation influences behavior.}

For the second premise, Wilcoxon Signed-rank test and Spearman rho were conducted between pairs of Social Dimensions (for trait level) or Cross-Dimensions (for sub-trait level) matched in such way that differences can theoretically be attributed to the influence of Social Stipulation while correlations statistically represent the stability of this influence (see complete results on

Appendix B).

On trait level, large significant differences were found $(\mathrm{z}=-12.75, \mathrm{p}<.001$, $\mathrm{r}_{\text {(equivalent })}=-0.52$ and $\left.\mathrm{z}=-12.58, \mathrm{p}<.001, \mathrm{r}_{\text {(equivalent })}=-0.51\right)$ along with equally large and significant correlations $\left(\mathrm{r}_{\mathrm{s}}=.841, \mathrm{p}<.001, \mathrm{z}^{\prime}=1.22\right.$ and $\mathrm{r}_{\mathrm{s}}=.725, \mathrm{p}<.001, \mathrm{z}^{\prime}$ $=0.92$ ). These results support the second premise at trait level.

For the sub-trait level, all eight comparisons yield statistically significant differences $(\mathrm{p}<.001)$ with moderate to strong practical effect $\left(\mathrm{r}_{(\text {equivalent }}\right)=-0.25$ to $0.55)$. This was paired by correlations $\left(r_{s}=.382\right.$ to .703$)$ that are all statistically significant at the alpha of .001 and has moderate to large effect size ranging from 0.40 to 87 . All these findings support the assumptions of Social Stipulation at subtrait level.

Altogether, scores were found to behave in line with how Cross D predicted Social Stipulation to exist and influence behavior. Evidences are more stable and more pronounced on the trait level than on sub-trait. 
Third Premise: Social Interaction influences behavior.

For the third premise, Wilcoxon Signed-rank Test and Spearman rho was conducted between pairs of Social Dimensions (for trait level) or Cross-Dimensions (for subtrait level) matched in such way that differences can be ascribed as the influence of Social Interaction while correlation represent the stability of this influence (see complete results on 
Appendix C).

For the trait level, statistically significant differences with moderate effect size were found $\left(\mathrm{z}=-11.22, \mathrm{p}<.001, \mathrm{r}_{\text {(equivalent })}=-0.46\right.$ and $\mathrm{z}=-10.84, \mathrm{p}<.001$, $\left.r_{\text {(equivalent })}=-0.44\right)$. The correlations were also significant with large effect size $\left(r_{\mathrm{s}}=\right.$ $.819, \mathrm{p}<.001, \mathrm{z}^{\prime}=1.15$ and $\left.\mathrm{r}_{\mathrm{s}}=.764, \mathrm{p}<.001, \mathrm{z}^{\prime}=1.01\right)$. These results all support the third premise at trait level.

For the sub-trait level, six out of eight comparisons yield statistically significant differences $(\mathrm{p}<.001)$ with varied degree of practical effect $\left(\mathrm{r}_{(\text {equivalent }}\right)=-$ 0.01 to -0.55$)$. However, correlations $\left(r_{\mathrm{s}}=.351\right.$ to .635$)$ are all statistically significant $(\mathrm{p}<.001)$ and has moderate to strong effect size ranging from 0.37 to 0.75 . The great majority these findings validates the assumptions of Social Interactions at sub-trait level.

In summary, the majority of results are in line with how Cross D predicted Social Interaction to manifest in scores, thereby supporting the third premise - Social Interaction influences behavior. Evidences are more pronounced on trait level than on sub-trait.

\section{Part 2: Cross-Dimensional framework does not compromise the reliability of the} test.

The impact of the framework on internal reliability was tested by conducting (1) within-test, (2) between-tests and (3) against-the-standard comparisons using APD values.

\section{Within-test Comparison}

For the first part, APD values of Social Scales scale were compared to Trait Scale's. Results were gathered as frequency and was converted to percentage. 
As shown in Figure 2,

Cross-Dimensions outperformed the whole test and Trait Components while Social

Dimensions tied with the whole test and comes close to Trait Components. This shows that

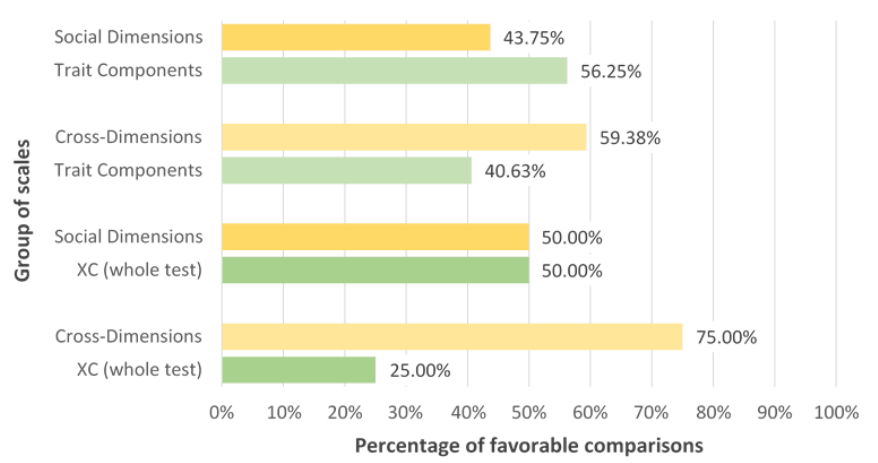

Figure 2. Summary of APD values comparisons per group of scales of $X C$

reliability tends to be better when the scale is trait-focused than when it is social-contextfocused. However, specificity in content, thereby regrouping the items into smaller units (i.e. Cross-Dimensions), tends to increase the reliability more dramatically.

\section{Between-tests Comparison}

Similar to the first part, APD values were compared, gathered as frequency then converted to percentage, but this time, $\mathrm{XC}$ scales were compared to IPIP NEO and BFI.

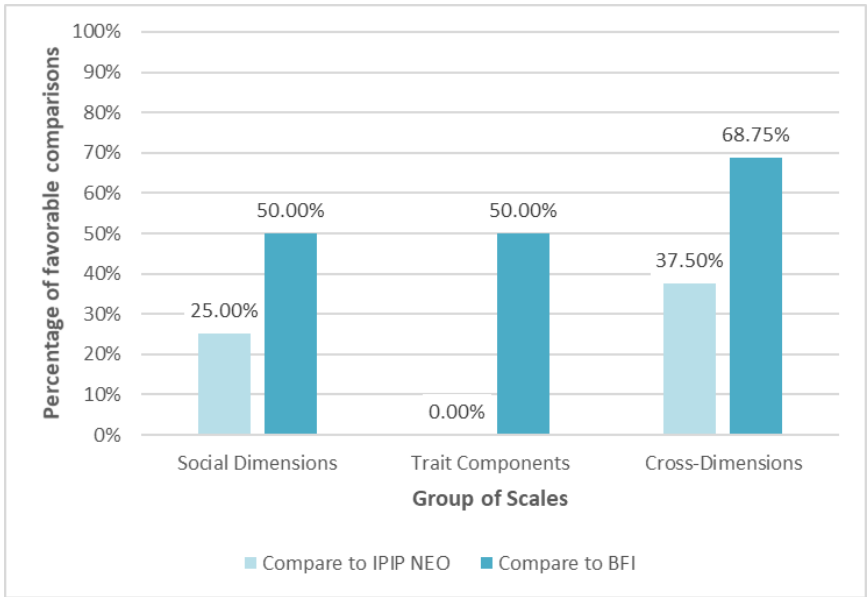

Figure 3. Summary of APD values comparisons between XC, IPIP NEO and BFI

As summarized in Figure

3, IPIP NEO have far much better reliability (62.50\% to 100\%) than XC scales. Nevertheless, XC scales shows comparable $(50.00 \%)$ to considerably better $(68.75 \%)$ reliability than BFI. This implies that to some extent, Cross D improves the reliability of the test as compare to traditional trait-focused approach on test development. 


\section{Against-the-standard Comparison}

To see if Cross D application compromised reliability, APD values were also evaluated in comparison to the standards (see p. 18 ).

As what can be seen in

Figure 4, all XC scales have APD

values greater than the average

range. Straightforwardly, this says

that Cross D does not compromise

the test's reliability; more so, it

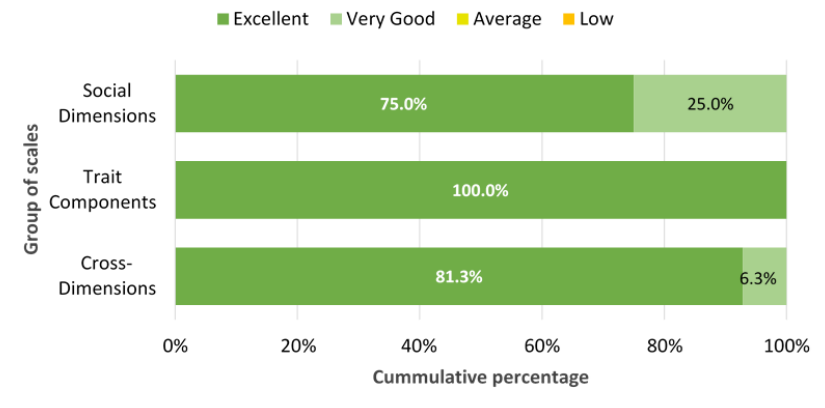

Figure 4. Distribution of APD values per group of scales of $X C$

improves the test's reliability as supported by findings from within-test and betweentest comparisons.

\section{Part 3: Cross-Dimensional framework improves the validity of the test.}

To tell whether the Cross D improved the test's validity, (1) within-test and (2) between-tests comparisons were conducted and to see if it did not compromised validity, (3) against-the-standard comparison of item validity was also performed.

\section{Within-test Comparison (of Concurrent Validity)}

After the comparison of concurrent validity values, results were collated as frequency and converted into percentage. Statistically significant differences $(p<0.05)$ were also separated from non-significant. 

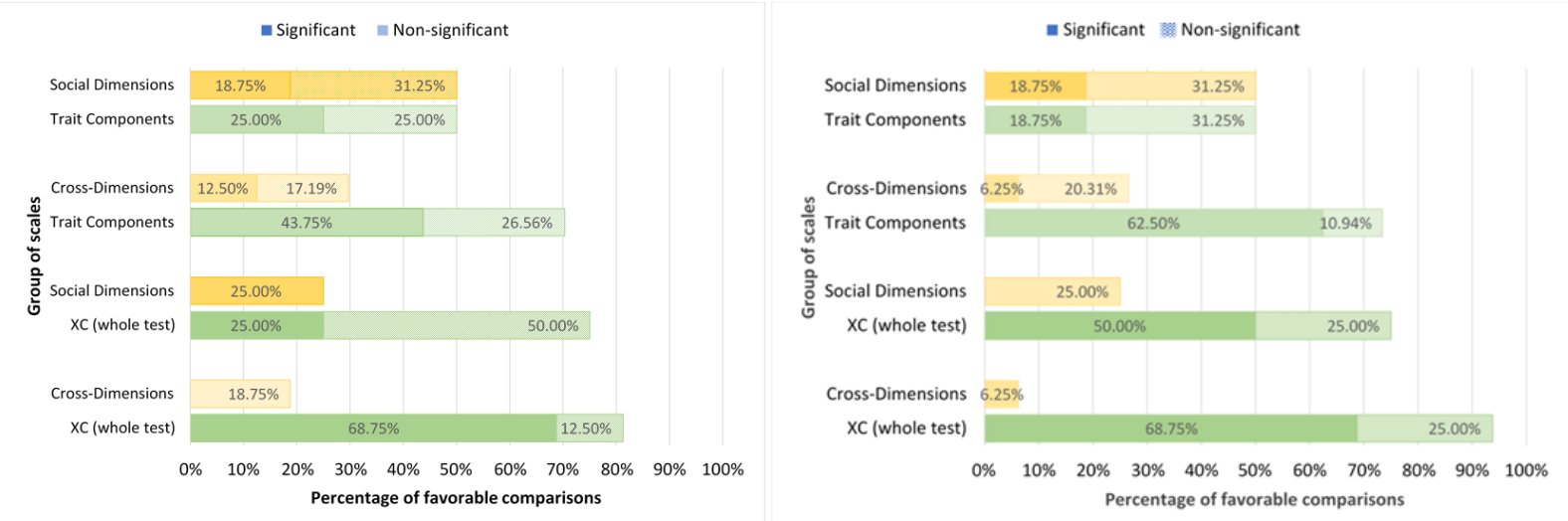

Figure 5. Summary of concurrent validity values comparisons with IPIP NEO (left) and BFI (right) Conscientiousness scale as criterion

As displayed in Figure 5, Trait Scales (in green) have better concurrent validity values as compared to Social Scales considering both significant and nonsignificant results. Thus, this reflects that Cross D could have decreased the validity of the test. However, it is interesting to note that scales with similar number of items - Social Dimensions and Trait Components - have almost equal validity.

\section{Between-tests Comparison (of Item Validity)}

For the second part, average item validity values of XC were compared to IPIP NEO's and BFI's. Similar to previous comparisons, the results were summarized as percentage.
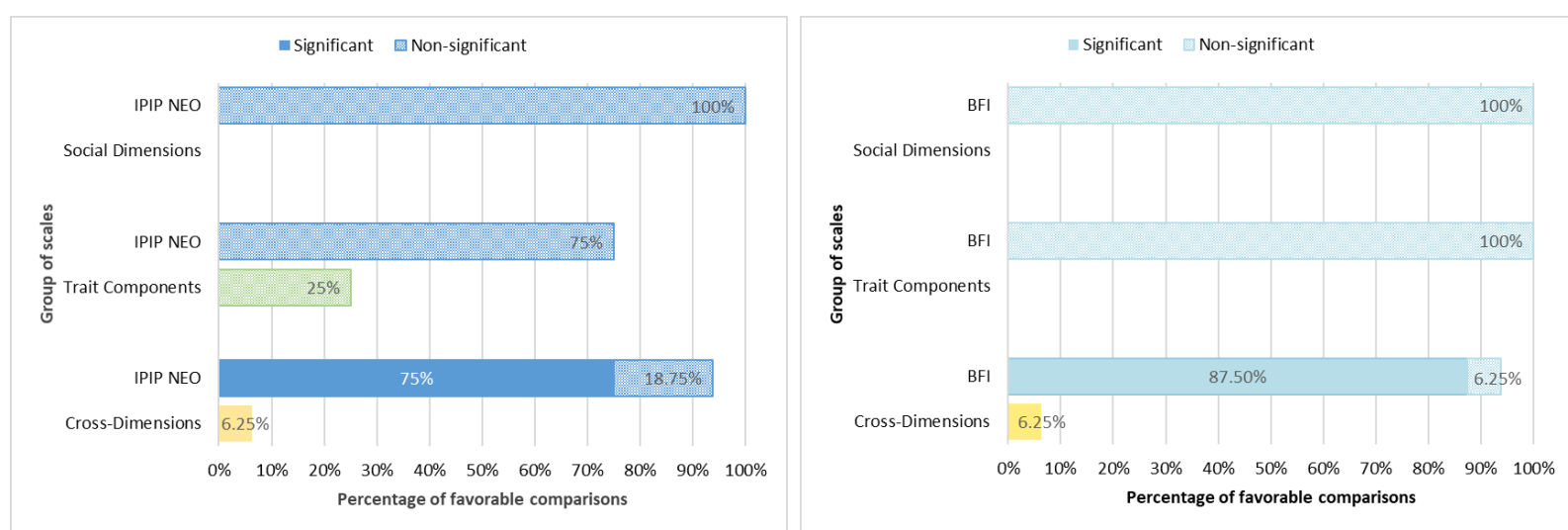

Figure 6. Summary of average item validity comparisons between XC scales and IPIP NEO (left) and BFI (right) Conscientiousness scale

Based on Figure 6, IPIP NEO and BFI have better average item validity than XC scales, but their leads are only significant with Cross-Dimensions. Nevertheless, 
this still supports the previous finding that says Cross D decreases the validity of the test in comparison to traditionally developed tests.

\section{Against-the-standard Comparison (of Item Validity)}

To see if the Cross D compromised the validity of the test with the reference to the standards (see p.19) . Results were presented in percentage on Figure 7.

Based on this, up to

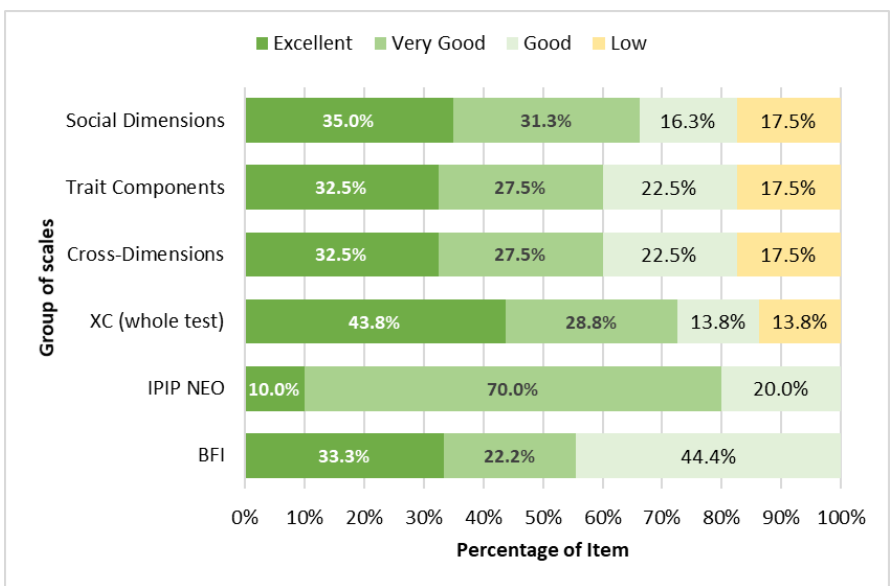

Figure 7. Distribution of item validity per group of scales $86.2 \%$ of (or 69 out of 80 ) XC items have acceptable item validity. This proportion makes the pool of items of XC acceptable in general.

For comparison, the $\mathrm{XC}$ scales have better ratio of items with excellent validity than IPIP NEO and BFI. However, all items of both IPIP NEO and BFI have acceptable item validity in contrast to $\mathrm{XC}$ with $13.8 \%$ to $17.5 \%$ items with poor validity. This implies that Cross D might have reduced the validity of the items.

\section{Discussion}

Ever since survey-type tests outdated lengthy interviews in the 1900s (Cohen \& Swerdlik, 2009), the advances in personality test development leaned towards statistical methods and exploration of traits to be included on standardized personality tests. As a result, the tradeoffs on using fixed sets of statements specifically, the dismissal of social context, were left unchecked. This went on amidst the rise of personality theories which factors in the situation (Bandura, 1997; Rotter, 1982), researches showing disparities in behavior as its social consequences change 
(London \& Oldham, 1977; Johnson \& Chang, 2006; Gardner, Gabriel, \& Lee, 1999), and studies dissecting behavioral changes during human interaction (Santiago \& Enriquez, 1976; Santiago, 1976).

As a resolution, Cross-Dimension Framework (Cross D) was devised to serve as a guide on incorporating social factors - namely, Social Stipulation and Social Interaction - on a personality inventory. After successful adaptation on a test named, CrossDimensional Conscientiousness Scale (XC), this paper examined the empirical basis of its (1) theoretical assumptions and its effect on (2) reliability and (3) validity of the test.

\section{Cross D and the Assumptions of Its Constructs}

As hypothesized in the first premise (p. 15), differences in scores were noted between scales that measure similar content (i.e., trait or sub-trait) but concern different Social Dimensions. Within the framework, these differences were credited to the unique combination of social factors in each Social Dimension and serve as proof of role difference. Such difference in expression of personality across social context was also suggested by literatures factoring in social circumstance (Bandura, 1997; Rotter, 1982), consequences of behavior (London \& Oldham, 1977; Johnson \& Chang, 2006; Gardner, Gabriel, \& Lee, 1999), and degree of interactions (Santiago \& Enriquez, 1976; Santiago, 1976). Moreover, these differences also show that the Social Dimensions are not only theoretical but also manifest on actual scores.

Interestingly, the scales with similar occurrence of a social factor (i.e. Social Stipulation or Social Interaction) were also found to be correlated despite the differences in scores (second and third premise, p.16-16). Using the proposed structure of Cross D to interpret these results, the similarity can be deduced as the shared social factors while the differences rose from the distinct combinations of these social factors. This consequently 
implies that the trait measured is not a mere lump of a whole but is a continuum with more specific, but not completely distinct parts.

\section{Effect of Cross D on Reliability}

It was also observed that the APD values improves as the unit becomes more specific (i.e. from whole test to Cross-Dimension) which is in line with the theoretical increase in homogeneity as the scope narrows down. Considering that $\mathrm{XC}$ items were grouped based on their content (which is a theory-based approach) rather than item statistic during the test development phase (Mercado, 2019b), this increase in reliability suggest that the structure of the scales (see Table 2 and Figure 1) are not only theoretical but are also statistically relevant. Additional research can be conducted to see if this specificity on content also increases the test-retest and inter-rater reliability.

Varied results were gathered from between-test APD comparison, but upon taking a closer look, the results can be best explained by the ratio of item retained to the initial item pool. The 50-item IPIP NEO was from 858 initial items, 44 items of BFI were from 300, while the 80 items of XC are from 500. Considering their APD values which are $.081, .143$, and .157 respectively, it can be observed that lower item retention rate leads to better APD value. This can be due to a wider selection for the best items to be included in the final form. Nonetheless, against-the-standard comparison showed that XC did not compromise the reliability of the test since all of its scales have acceptable APD values.

\section{Effect of Cross D on Validity}

It was also found that the test produced lower concurrent and item validity values than those developed in traditional way. Despite this, the values still generally meet the standard cutoffs. While this seems to be a drawback, in hindsight, it is theoretically inevitable. Since social factors can be considered as constructs themselves, infusing them 
to a personality scale will "reduce" the scale's validity. That is because, strictly speaking, the Cross D-aligned items do not measure what it is "only" supposed to measure (i.e. the trait); the items also consider the social aspects of the behavior. Within Domain-Sampling Theory, Cross D can be seen as an "expansion" on a construct that traditionally developed tests cover. This expansion creates a mismatch in scope which shows as lower validity values.

This explanation was also supported by the comparisons of concurrent validity favorable to the Trait Scales over Social Scales as shown in Figure 5. It can be recalled that Trait Scales has characteristics closer to traditional tests since it focuses on the trait more than the social context (p. 11).

Perhaps, a more appropriate research design can shed a light on this in the future; one which can compare a single trait as repeatedly measured by a traditionally developed test but across social settings and as measured by a Cross D-based test. Such study will also further evaluate the evidence for construct validity (Cronbach \& Meehl, 1955) of Cross D social factors and social settings.

\section{Limitations and Recommendations}

Overall, this study showed indications of the framework's capacity to integrate social factors on personality assessment. It also provided statistical evidence for the framework's assumptions and efficiency by attesting to the existence of social factors and to the efficiency of its proposed social setting taxonomy.

The systematic incongruence found on scores across Social Dimensions also challenges the mindset that personality only changes over time and pushes for escalation of social factors as an inevitable component on personality assessment (rather than an extraneous variable) - a matter that can be addressed through Cross D application. 
Replication of the study with other traits and using a larger sample representative of the population can best reevaluate these conclusions. 


\section{References}

Allport, G. W. (1937). Personality: A psychological interpretation. New York: Henry Holt. Allport, G. W. (1961). Pattern and growth in personality. New York: Holt, Rinehart and Winston.

Bandura, A. (1997). Self-efficacy: The exercise of control. New York: Freeman.

Borsboom, D., Mellenbergh, G. J., \& van Heerden, J. (2004). The Concept of Validity. Psychological Review, 111(4), 1061-1071. doi: 10.1037/0033-295X.111.4.1061

Campbell, D. T., \& Fiske, D. W. (1959). Convergent and Discriminant Validation by the Multitrait-Multimethod Matrix. Psychological Bulletin, 56(2), 81-105.

Carlota, A. (1985). The development of the Panukat ng Pagkataong Pilipino (PPP). Philippine Journal of Educational Measurement, 4(1), 55-68. Retrieved from https://www.cem-inc.org.ph/

Cattell, R. B. (1949). Manual for Forms A and B: Sixteen Personality Factors Questionnaire. Champaign, IL: IPAT.

Clark, L. A., \& Watson, D. (1995). Constructing Validity: Basic Issues in Objective Scale Development. Psychological Assessment, 7(3), 309-319. doi:10.1037/10403590.7.3.309

Cohen, R. J., \& Swerdlik, M. E. (2009). Psychological Testing and Assessment: An Introduction to Tests and Measurement, 7th Edition. USA: McGraw-Hill Primis.

Costa, P. T., \& McCrae, R. R. (1995). Domains and facets: Hierarchical personality assessment using the Revised NEO Personality Inventory. Journal of personality assessment, 64(1), 21-50. doi:10.1207/s15327752jpa6401_2

Cristobal, E., Flavián, C., \& Guinaliu, M. (2007). Perceived e-service quality (PeSQ). Managing Service Quality: An International Journal, 17(3), 317-340. doi:10.1108/09604520710744326

Cronbach, L. J., \& Meehl, P. E. (1955). Construct Validity in Psychological Tests. Psyhological Bulletin, 52(4), 281-302.

Del Pilar, G. E. (2017). The Development of the Masaklaw na Panukat ng Loob (Mapa ng Loob). Philippine Journal Of Psychology, 50(1), 103-141.

Enriquez, V. G. (1978a). Kapwa: A core concept in Filipino social psychology. Philippine Social Sciences and Humanities Review, 42(1-4), 100-108. 
Enriquez, V. G. (1978b). Sikolohiyang Pilipino: Batayan sa Kasaysayan, Perspektibo, Mga Konsepto at Bibliograpiya. [Filipino Psychology: Historical Basis, Perspectives, Concepts and Bibliography]. Quezon City: Philippine Psychology Research House.

Enriquez, V. G. (1997). Filipino psychology: Concepts and methods. Asian perspectives on psychology, 19, 40-53.

Eysenck, H. J., \& Eysenck, S. B. (1975). Manual of the Eysenck Personality Qyestionnaire(Junior and Adult). London: Hodder \& Stoughton.

Feist, J., \& Feist, G. J. (2008). Theories of Personality, 7th Edition. USA: McGraw-Hill Primis.

Gardner, W. L., Gabriel, S., \& Lee, A. Y. (1999, July). "I" Value Freedom, but "We" Value Relationships: Self-Construal Priming Mirrors Cultural Differences in Judgment. Psychological Science, 10(4), 321-326. Retrieved from http://www.jstor.com/stable/40063438

Goodhue, D. L., \& Loiacono, E. T. (2002). Randomizing Survey Question Order Vs. Grouping Questions by Construct: An Empirical Test of the Impact On Apparent Reliabilities and Links to Related Constructs. Proceedings of the 35th Hawaii International Conference on System Sciences. Hawaii: IEEE Computer Society. doi:10.1109/hicss.2002.994385

Gurven, M., von Rueden, C., Massenkoff, M., Vie, M. L., \& Kaplan, H. (2013). How Universal Is the Big Five? Testing the Five-Factor Model of Personality Variation Among Forager-Farmers in the Bolivian Amazon. Journal of Personality and Social Psychology, 104(2), 354-370.

Hee, O. C. (2014, April). Validity and Reliability of the Big Five Personality Traits Scale in Malaysia. International Journal of Innovation and Applied Studies, 5(4), 309-315.

Hinkin, T. R. (1995). A Review of Scale Development Practices in the Study of Organizations. Journal of Management, 21(5), 967-988. doi:10.1177/014920639502100509

Howard, K. I., \& Forehand, G. A. (1962). A Method for Correcting Item-Total Correlation for the Effect of Relevant Item Inclusion. Educational and Psychological Measurement, 22(4), 731-735. doi:10.1177/001316446202200407

International Personality Item Pool. (2019, September 23). Short Form for the IPIP-NEO: International Personality Item Pool Representation of the NEO PI-R. Retrieved from International Personality Item Pool: A Scientific Collaboratory for the 
Development of Advanced Measures of Personality and Other Individual Differences: https://ipip.ori.org/new_ipip-50-item-scale.htm

John, O. P., Naumann, L. P., \& Soto, C. J. (2008). Paradigm Shift to the Integrative Big-Five Trait Taxonomy: History, Measurement, and Conceptual Issues. In O. P. John, R. W. Robins, \& L. A. Pervin, Handbook of personality: Theory and research (pp. 114-158). New York: Guilford Press.

John, O., \& Srivastava, S. (1999). The Big-Five trait taxonomy: History, measurement and theoretical perspective. In O. John, \& L. Pervin, Handbook of personality: Theory and research (pp. 102-138). New York: Guilford.

Johnson, R. E., \& Chang, C.-H. (2006, August). "I" is to continuance as "We" is to affective: the relevance of the self-concept for organizational commitment. Journal of Organizational Behavior, 27(5), 549-570. Retrieved from https://www.jstor.org/stable/4093919?seq=1

Katigbak, M. S., Church, A. T., Guanzon-Lapena, M. A., Carlota, A. J., \& del Pilar, G. H. (2002). Are Indigenous Personality Dimensions Culture Specific? Philippine Inventories and the Five-Factor Model. Journal of Personality and Social Psychology, 82(1), 89-101. doi:10.1037//0022-3514.82.1.89

Lenhard, W., \& Lenhard, A. (2014). Hypothesis Tests for Comparing Correlations. doi:10.13140/RG.2.1.2954.1367

Loiacono, E. T., Watson, R. T., \& \& Goodhue, D. L. (2002). WebQual: A measure of website quality. 13, pp. 432-437. ProQuest on behalf of American Marketing Association. Retrieved from https://search.proquest.com/docview/199486360/fulltextPDF/734A321AA99849A4 $\mathrm{PQ} / 1$ ?accountid=10098

London, M., \& Oldham, G. R. (1977, March). A Comparison of Group and Individual Incentive Plans. The Academy of Management Journal, 20(1), 34-41. Retrieved from http://www.jstor.com/stable/255460

McCrae, R. R. (2002). Cross-cultural research on the five-factor model of personality. In W. J. Lonner, D. L. Dinnel, S. A. Hayes, \& D. N. Sattler, Online readings in psychology and culture (Unit 6, Chapter 1). Retrieved from http://www.wwu.edu/ culture

McCrae, R. R., \& Costa, P. T. (1999). A Five-Factor Theory of Personality. In L. A. Pervin, \& O. P. John, Personality theory and research (pp. 139-153). New York: Guilford Press. 
McCrae, R. R., \& Costa, P. T. (2003). Personality in adulthood: A five-factor theory perspective - Second Edition. New York: Guilford Press.

McCrae, R. R., Terracciano, A., \& Project, 7. M. (2005). Universal features of personality traits from the observer's perspective: Data from 50 cultures. Journal of Personality and Social Psychology, 88(3), 547-561. doi:10.1037/00223514.88.3.547

Mercado, A. M. (2019a). Filipino Test Development Approach: Validation Study of CrossDimensional Framework. Inclusive Psychology: Valuing Diversity and Accomodation Among Filipinos (pp. 63-64). Davao City, Philippines: Psychological Association of the Philippines.

Mercado, A. M. (2019b). Cross-Dimensional Conscientiousness Scale - Revised. Makati City, Philippines: University of Makati.

Mussel, P., Gatzka, T., \& Hewig, J. (2018). Situational Judgment Tests as an Alternative Measure for Personality Assessment. European Journal of Psychological Assessment, 34(5), 328-335. doi:10.1027/1015-5759/a000346

Nurosis, M. (1994). Statistical Data Analysis. Chicago, IL: SPSS Inc.

OpenStax. (2016). Psychology. Texas: Rice University.

Paredes-Canilao, N., \& Babaran-Diaz, M. A. (2013). Sikolohiyang Pilipino: 50 years of critical-emancipatory social science in the Philippines. Annual Review of Critical Psychology, 10, 765-783.

Parry, H. J., \& Crossley, H. M. (1950). Validity of Responses to Survey Questions. The Public Opinion Quarterly, 14(1), 61-80. Retrieved from https://www.jstor.org/stable/2745899

Pe-pua, R., \& Protacio-Marcelino, E. (2000). Sikolohiyang Filipino: A Legacy of Virgilio Enriquez. Asian Journal of Social Psychology, 49-71. doi:10.1111/1467839X.00054

Rauthmann, J. F., Gallardo-Pujol, D., Guillaume, E. M., Todd, E., Nave, C. S., Sherman, R. A., ... Funder, D. C. (2014). The Situational Eight DIAMONDS: A Taxonomy of Major Dimensions of Situation Characteristics. American Psychological Association, 107(4), 677-718. doi:dx.doi.org/10.1037/a0037250

Rosenthal, R. (1994). Parametric measures of effect size. In H. Cooper, \& L. V. Hedges (Eds.), The handbook of research synthesis (pp. 231-244). New York: Russell Sage Foundation. 
Rotter, J. B. (1982). The development and applications of social learning theory: Selected papers. New York: Praeger.

Santiago, C. (1976). The language of food. (G. F. Cordero, Ed.) Culinary Culture of the Philippines.

Santiago, C., \& Enriquez, V. G. (1976). Tungo sa Makapilipinong Pananaliksik. Sikolohiyang Pilipino: Mga Ulat at Balita, I(4).

Schmitt, D. P., Allik, J., McCrae, R. R., Benet-Martínez, V., Alcalay, L., \& Ault, L. (2007). The geographic distribution of Big Five personality traits: Patterns and profiles of human self description across 56 nations. Journal of Cross-Cultural Psychology, 38(2), 173-212. doi:10.1177/0022022106297299

Sturman, E. D., Cribbie, R. A., \& Flett, G. L. (2009). The Average Distance between Item Values: A Novel Approach for Estimating Internal Consistency. Journal of Psychoeducational Assessment, 27(5), 409-420. doi:10.1177/0734282908330937

Triandis, H., \& Gelfand, M. (1998, January). Converging measurement of horizontal and vertical individualism and collectivism. Journal of Personality and Social Psychology, 74(1), 118-128. doi:10.1037/0022-3514.74.1.118

Wolfinbarger, M., \& Gilly, M. C. (2003). eTailQ: Dimensionalizing, Measuring and Predicting etail Quality. Journal of Retailing, 79(3), 183-198. doi:10.1016/S00224359(03)00034-4

Ypofanti, M., Zisi, V., Zourbanos, N., Mouchtouri, B., Tzanne, P., Theodorakis, Y., \& \& Lyrakos, G. (2015). Psychometric Properties of the International Personality Item Pool Big-Five Personality Questionnaire for the Greek population. Health psychology research, 3(2), 2206. doi:10.4081/hpr.2015.2206

Ziegler, M., Horstmann, K. T., \& Ziegler, J. (2019). Personality in Situations: Going Beyond the OCEAN and Introducing the Situation Five. American Psychological Association, 31(4), 567-580. doi:dx.doi.org/10.1037/pas0000654 


\section{Appendices}

\section{Appendix A: Test of Difference between Social Dimensions and Cross-Dimensions}

\section{Appendix A.1}

Friedman Tests Statistics between Social Dimensions and Cross-Dimensions

\begin{tabular}{|c|c|c|c|c|c|}
\hline \multirow[t]{2}{*}{ Statistics } & \multirow{2}{*}{$\begin{array}{l}\text { Trait level }^{\text {a }} \\
\text { Conscientiousness }^{-}\end{array}$} & \multicolumn{4}{|c|}{ Sub-trait level ${ }^{b}$} \\
\hline & & Aptitude & Orderliness & Commitment & Deliberation \\
\hline Chi-Square & 447.13 & 241.98 & 351.89 & 221.17 & 358.17 \\
\hline Df & 3 & 3 & 3 & 3 & 3 \\
\hline Asymp. Sig. & $<.001$ & $<.001$ & $<.001$ & $<.001$ & $<.001$ \\
\hline Kendall's W & $.490^{\bullet \bullet}$ & $.265^{\bullet \bullet}$ & $.386^{\bullet \bullet}$ & $.243^{\bullet \bullet}$ & $.393^{\bullet \bullet}$ \\
\hline
\end{tabular}

${ }^{a}$ with Social Dimensions as groups

${ }^{\mathrm{b}}$ with Cross-Dimensions as groups

$\bullet$ Small effect $\bullet$ Moderate effect $\bullet \bullet$ Strong effect

$\mathrm{n}=304$ 


\section{Appendix A.2}

Post Hoc: Wilcoxon Signed-Rank Tests Statistics between Social Dimensions and Cross-Dimensions

\begin{tabular}{|c|c|c|c|c|}
\hline \multicolumn{5}{|c|}{ Trait level: Between Conscientiousness Social Dimensions } \\
\hline & 1 & 2 & 3 & 4 \\
\hline 1. Personal Conscientiousness & & $-12.75^{\mathrm{a}^{* * * *}}$ & $-14.63^{a^{* * * *}}$ & $-11.22^{\mathrm{a}^{* * * *}}$ \\
\hline 2. Individual Conscientiousness & & & $-10.84^{\mathrm{a}^{* * * *}}$ & $-4.37^{b^{* * *}}$ \\
\hline $\begin{array}{l}\text { 3. Professional } \\
\text { Conscientiousness }\end{array}$ & & & & $-12.58^{b^{* * *}}$ \\
\hline \multicolumn{5}{|l|}{ 4. Relational Conscientiousness } \\
\hline \multicolumn{5}{|c|}{ Sub-trait level: Between Aptitude Cross-Dimensions } \\
\hline & 1 & 2 & 3 & 4 \\
\hline 1. Personal Aptitude & & $-7.29^{\mathrm{a}^{* * *}}$ & $-6.33^{a^{* * *}}$ & $-12.68^{a^{* * *}}$ \\
\hline 2. Individual Aptitude & & & $-0.37^{\mathrm{b}}$ & $-8.39^{\mathrm{a}^{* * *}}$ \\
\hline 3. Professional Aptitude & & & & $-8.98^{a^{* * *}}$ \\
\hline \multicolumn{5}{|l|}{ 4. Relational Aptitude } \\
\hline \multicolumn{5}{|c|}{ Sub-trait level: Between Orderliness Cross-Dimensions } \\
\hline & 1 & 2 & 3 & 4 \\
\hline 1. Personal Orderliness & & $-8.26^{\mathrm{a}^{* * *}}$ & $-13.77^{a^{* * *}}$ & $-4.30^{\mathrm{a}^{\mathrm{*} * *}}$ \\
\hline 2. Individual Orderliness & & & $-11.69^{a^{* * *}}$ & $-5.15^{\mathrm{b}^{* * *}}$ \\
\hline 3. Professional Orderliness & & & & $-12.94^{\mathrm{b}^{* * *}}$ \\
\hline \multicolumn{5}{|l|}{ 4. Relational Orderliness } \\
\hline \multicolumn{5}{|c|}{ Sub-trait level: Between Commitment Cross-Dimensions } \\
\hline & 1 & 2 & 3 & 4 \\
\hline 1. Personal Commitment & & $-6.17^{\mathrm{a}^{* * *}}$ & $-12.01^{\mathrm{a}^{* * *}}$ & $-4.21^{\mathrm{a}^{* * *}}$ \\
\hline 2. Individual Commitment & & & $-8.97^{\mathrm{a}^{* * *}}$ & $-2.20^{b^{*}}$ \\
\hline 3. Professional Commitment & & & & $-10.06^{b^{* * *}}$ \\
\hline 4. Relational Commitment & & & & \\
\hline
\end{tabular}

Sub-trait level: Between Deliberation Cross-Dimensions

\begin{tabular}{|c|c|c|c|c|}
\hline & 1 & 2 & 3 & 4 \\
\hline 1. Personal Deliberation & & $-10.55^{\mathrm{a}^{* * *}}$ & $-13.53^{a^{* * * *}}$ & $-0.14^{\mathrm{a}}$ \\
\hline 2. Individual Deliberation & & & $-7.63^{\mathrm{a}^{* * * *}}$ & $-10.02^{b^{* * *}}$ \\
\hline 3. Professional Deliberation & & & & $-13.60^{b^{* * *}}$ \\
\hline 4. Relational Deliberation & & & & \\
\hline
\end{tabular}

Note: in bold text are results significant at LDS p-value of .008 (using Bonferroni correction)

${ }^{a}$ Based on positive ranks; mean rank of row item < mean rank of column item

${ }^{\mathrm{b}}$ Based on negative ranks; mean rank of row item $>$ mean rank of column item

$* \mathrm{p}<.05, * * \mathrm{p}<.01, * * * \mathrm{p}<.001$

$\bullet$ Small effect $\bullet \bullet$ Moderate effect $\bullet \bullet$ Strong effect $\mathrm{n}=304$ 


\section{Appendix B.}

Statistical Indications of Social Stipulation (SS) on Trait Expression for Trait and Sub-trait Level

\begin{tabular}{|c|c|c|c|c|c|}
\hline \multicolumn{6}{|c|}{ Trait level: Conscientiousness Social Dimensions } \\
\hline & \multicolumn{2}{|c|}{ Wilcoxon SRT } & \multicolumn{2}{|c|}{ Spearman rho } & \multirow{2}{*}{$\begin{array}{l}\text { Supports SS } \\
\text { assumptions? }\end{array}$} \\
\hline & $\mathrm{Z}$ & $r_{\text {(equivalent) }}$ & $r_{s}$ & z' & \\
\hline Individual Cons. - Personal Cons. & $-12.75^{\mathrm{a}^{* * *}}$ & $-0.52^{\bullet \bullet \bullet}$ & & & Yes \\
\hline Relational Cons. - Professional Cons. & $-12.58^{b^{* * *}}$ & $-0.51 \bullet \bullet$ & & & Yes \\
\hline Relational Cons. - Personal Cons. & & & $.841^{* * *}$ & $1.22^{\bullet \bullet \bullet}$ & Yes \\
\hline Professional Cons. - Individual Cons. & & & $.725^{* * *}$ & $0.92^{\bullet \bullet \bullet}$ & Yes \\
\hline \multicolumn{6}{|c|}{ Sub-trait level: Aptitude Cross-Dimensions } \\
\hline Individual Apt. - Personal Apt. & $-7.29^{\mathrm{a}^{* * * *}}$ & $-0.30^{\bullet \bullet}$ & & & Yes \\
\hline Relational Apt. - Professional Apt. & $-8.98^{a^{* * *}}$ & $-0.36^{\bullet \bullet}$ & & & Yes \\
\hline Relational Apt. - Personal Apt. & & & $.550^{* * *}$ & $0.62^{\bullet \bullet \bullet}$ & Yes \\
\hline Professional Apt. - Individual Apt. & & & $.703^{* * *}$ & $0.87^{\bullet \bullet \bullet}$ & Yes \\
\hline \multicolumn{6}{|c|}{ Sub-trait level: Orderliness Cross-Dimensions } \\
\hline Individual Ord. - Personal Ord. & $-8.26^{\mathrm{a}^{* * *}}$ & $-0.33^{\bullet \bullet}$ & & & Yes \\
\hline Relational Ord. - Professional Ord. & $-12.94^{b^{* * *}}$ & $-0.52 \cdots$ & & & Yes \\
\hline Relational Ord. - Personal Ord. & & & $.592^{* * *}$ & $0.68^{\bullet \bullet \bullet}$ & Yes \\
\hline Professional Ord. - Individual Ord. & & & $.557^{* * *}$ & $0.63^{\bullet \bullet \bullet}$ & Yes \\
\hline \multicolumn{6}{|c|}{ Sub-trait level: Commitment Cross-Dimensions } \\
\hline Individual Com. - Personal Com. & $-6.17^{7^{* * *}}$ & $-0.25^{\bullet \bullet}$ & & & Yes \\
\hline Relational Com. - Professional Com. & $-10.06^{\mathrm{b} * * *}$ & $-0.41^{\bullet \bullet}$ & & & Yes \\
\hline Relational Com.- Personal Com. & & & $.656^{* * *}$ & $0.79^{\bullet \bullet \bullet}$ & Yes \\
\hline Professional Com. - Individual Com. & & & $.526^{* * *}$ & $0.58^{\bullet \bullet \bullet}$ & Yes \\
\hline \multicolumn{6}{|c|}{ Sub-trait level: Deliberation Cross-Dimensions } \\
\hline Individual Del. - Personal Del. & $-10.55^{\mathrm{a}^{* * * *}}$ & $-0.43^{\bullet \bullet}$ & & & Yes \\
\hline Relational Del. - Professional Del. & $-13.60^{b^{* * *}}$ & $-0.55 \bullet \bullet$ & & & Yes \\
\hline Relational Del. - Personal Del. & & & $.592^{* * * *}$ & $0.68^{\bullet \bullet \bullet}$ & Yes \\
\hline Professional Del. - Individual Del. & & & $.382^{* * *}$ & $0.40^{\bullet \bullet}$ & Yes \\
\hline
\end{tabular}

Note: $r_{\mathrm{s}}=$ Spearman rho with Fisher's $\mathrm{z}$ as effect size

Wilcoxon Signed-rank Test with $\mathbf{r}_{\text {(equivalent) }}$ as effect size based on Rosenthal (1994)

a Based on positive ranks; mean rank of former $>$ mean rank of later

${ }^{\mathrm{b}}$ Based on negative ranks; mean rank of former $<$ mean rank of later

$* \mathrm{p}<.05, * * \mathrm{p}<.01, * * * \mathrm{p}<.001$

- Small effect ${ }^{\bullet}$ Moderate effect $\bullet \bullet$ Strong effect $\mathrm{n}=304$ 


\section{Appendix C.}

Statistical Indications of Social Interaction (SI) on Trait Expression for Trait and Sub-trait level

\begin{tabular}{|c|c|c|c|c|c|}
\hline \multicolumn{6}{|c|}{ Trait level: Conscientiousness Social Dimensions } \\
\hline & \multicolumn{2}{|c|}{ Wilcoxon SRT } & \multicolumn{2}{|c|}{ Spearman rho } & \multirow{2}{*}{$\begin{array}{l}\text { Supports SI } \\
\text { assumptions? }\end{array}$} \\
\hline & $\mathrm{Z}$ & $\mathrm{r}$ & $\mathrm{r}_{\mathrm{s}}$ & $z^{\prime}$ & \\
\hline Relational Cons. - Personal Cons. & $-11.22^{\mathrm{a}^{* * *}}$ & $-0.46^{\bullet \bullet}$ & & & Yes \\
\hline Professional Cons. - Individual Cons. & $-10.84^{\mathrm{a}^{* * *}}$ & $-0.44^{\bullet \bullet}$ & & & Yes \\
\hline Individual Cons. - Personal Cons. & & & $.819^{* * *}$ & $1.15^{\bullet \bullet \bullet}$ & Yes \\
\hline Relational Cons. - Professional Cons. & & & $.764^{* * *}$ & $1.01^{\bullet \bullet \bullet}$ & Yes \\
\hline \multicolumn{6}{|c|}{ Sub-trait level: Aptitude Cross-Dimensions } \\
\hline Relational Apt. - Personal Apt. & $-12.68^{a^{* * *}}$ & $-0.51^{\bullet \bullet \bullet}$ & & & Yes \\
\hline Professional Apt. - Individual Apt. & $-0.37^{\mathrm{b}}$ & -0.02 & & & No \\
\hline Individual Apt. - Personal Apt. & & & $.635^{* * *}$ & $0.75^{\bullet \bullet \bullet}$ & Yes \\
\hline Relational Apt. - Professional Apt. & & & $.515^{* * *}$ & $0.57^{\bullet \bullet \bullet}$ & Yes \\
\hline \multicolumn{6}{|c|}{ Sub-trait level: Orderliness Cross-Dimensions } \\
\hline Relational Ord. - Personal Ord. & $-4.30^{\mathrm{a}^{* * *}}$ & -0.17 & & & Yes \\
\hline Professional Ord. - Individual Ord. & $-11.69^{a^{* * *}}$ & $-0.47^{\bullet \bullet}$ & & & Yes \\
\hline Individual Ord. - Personal Ord. & & & $.508^{* * *}$ & $0.56^{\bullet \bullet \bullet}$ & Yes \\
\hline Relational Ord. - Professional Ord. & & & $.523^{* * *}$ & $0.58^{\bullet \bullet \bullet}$ & Yes \\
\hline \multicolumn{6}{|c|}{ Sub-trait level: Commitment Cross-Dimensions } \\
\hline Relational Com. - Personal Com. & $-4.21^{\mathrm{a}^{* * *}}$ & -0.17 & & & Yes \\
\hline Professional Com. - Individual Com. & $-8.97^{\mathrm{a}^{* * *}}$ & $-0.36^{\bullet \bullet}$ & & & Yes \\
\hline Individual Com. - Personal Com. & & & $.579^{* * *}$ & $0.66^{\bullet \bullet \bullet}$ & Yes \\
\hline Relational Com. - Professional Com. & & & $.553^{* * *}$ & $0.62^{\bullet \bullet \bullet}$ & Yes \\
\hline \multicolumn{6}{|c|}{ Sub-trait level: Deliberation Cross-Dimensions } \\
\hline Relational Del. - Personal Del. & $-0.14^{\mathrm{d}}$ & -0.01 & & & No \\
\hline Professional Del. - Individual Del. & $-7.63^{d^{* * *}}$ & $-0.31^{\bullet \bullet}$ & & & Yes \\
\hline Individual Del. - Personal Del. & & & $.351^{* * *}$ & $0.37^{\bullet \bullet}$ & Yes \\
\hline Relational Del. - Professional Del. & & & $.549^{* * *}$ & $0.62^{\bullet \bullet \bullet}$ & Yes \\
\hline
\end{tabular}

Note: $r_{\mathrm{s}}=$ Spearman rho with Fisher's $\mathrm{z}$ as effect size

Wilcoxon Signed-rank Test with $r_{\text {(equivalent) }}$ as effect size based on Rosenthal (1994)

${ }^{a}$ Based on positive ranks; mean rank of former $>$ mean rank of later

${ }^{\mathrm{b}}$ Based on negative ranks; mean rank of former $<$ mean rank of later

$* \mathrm{p}<.05, * * \mathrm{p}<.01, * * * \mathrm{p}<.001$

$\bullet$ Small effect $\bullet \bullet$ Moderate effect $\bullet \bullet$ Strong effect

$\mathrm{n}=304$ 
Appendix D.

$A P D$ and Average Item Validity of XC, IPIP NEO, and BFI

\begin{tabular}{|c|c|c|c|c|c|}
\hline \multirow[t]{2}{*}{ Scale } & \multirow[t]{2}{*}{$\begin{array}{l}\text { No. of } \\
\text { items }\end{array}$} & \multicolumn{2}{|l|}{ APD } & \multicolumn{2}{|c|}{$\begin{array}{l}\text { Average item } \\
\text { validity }\end{array}$} \\
\hline & & Value & Description & Value & Description \\
\hline \multicolumn{6}{|l|}{ Social Dimensions } \\
\hline Personal Conscientiousness & 20 & .081 & Excellent & .429 & Good \\
\hline Individual Conscientiousness & 20 & .113 & Excellent & .416 & Good \\
\hline Professional Conscientiousness & 20 & .206 & Very good & .392 & Average \\
\hline Relational Conscientiousness & 20 & .203 & Excellent & .420 & Good \\
\hline \multicolumn{6}{|l|}{ Trait Components } \\
\hline Aptitude & 20 & .096 & Excellent & .447 & Good \\
\hline Orderliness & 20 & .155 & Excellent & .390 & Average \\
\hline Commitment & 20 & .127 & Excellent & .390 & Average \\
\hline Deliberation & 20 & .162 & Excellent & .384 & Average \\
\hline \multicolumn{6}{|l|}{ Cross-Dimensions } \\
\hline Personal Aptitude & 5 & .054 & Excellent & .294 & Low \\
\hline Personal Orderliness & 5 & .086 & Excellent & .347 & Average \\
\hline Personal Commitment & 5 & .058 & Excellent & .288 & Low \\
\hline Personal Deliberation & 5 & .132 & Excellent & .365 & Average \\
\hline Individual Aptitude & 5 & .043 & Excellent & .562 & Excellent \\
\hline Individual Orderliness & 5 & .111 & Excellent & .270 & Low \\
\hline Individual Commitment & 5 & .142 & Excellent & .309 & Average \\
\hline Individual Deliberation & 5 & .171 & Excellent & .137 & Low \\
\hline Professional Aptitude & 5 & .067 & Excellent & .384 & Average \\
\hline Professional Orderliness & 5 & .293 & Average & .224 & Low \\
\hline Professional Commitment & 5 & .271 & Average & .145 & Low \\
\hline Professional Deliberation & 5 & .240 & Very good & .357 & Average \\
\hline Relational Aptitude & 5 & .140 & Excellent & .224 & Low \\
\hline Relational Orderliness & 5 & .156 & Excellent & .346 & Average \\
\hline Relational Commitment & 5 & .053 & Excellent & .329 & Average \\
\hline Relational Deliberation & 5 & .033 & Excellent & .377 & Average \\
\hline Conscientiousness & 80 & .157 & Excellent & .434 & Good \\
\hline IPIP NEO ${ }^{a}$ & 10 & .081 & Excellent & .440 & Good \\
\hline $\mathrm{BFI}^{\mathrm{a}}$ & 9 & .143 & Excellent & .456 & Good \\
\hline 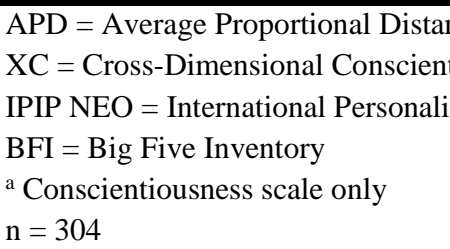 & $\begin{array}{l}\text { ess Scale } \\
\text { n Pool Re }\end{array}$ & entation & the NEO PI-R & & \\
\hline
\end{tabular}


Appendix E.

Concurrent Validity of XC scales

\begin{tabular}{|c|c|c|c|}
\hline \multirow[t]{2}{*}{ Scale } & \multirow{2}{*}{$\begin{array}{l}\text { No. of } \\
\text { items }\end{array}$} & \multicolumn{2}{|l|}{ Criterion } \\
\hline & & IPIP NEO $^{a}$ & $\mathrm{BFI}^{\mathrm{a}}$ \\
\hline \multicolumn{4}{|l|}{ Social Dimensions } \\
\hline Personal Conscientiousness & 20 & .565 & .585 \\
\hline Individual Conscientiousness & 20 & .436 & .481 \\
\hline Professional Conscientiousness & 20 & .358 & .464 \\
\hline Relational Conscientiousness & 20 & .464 & .483 \\
\hline \multicolumn{4}{|l|}{ Trait Components } \\
\hline Aptitude & 20 & .577 & .606 \\
\hline Orderliness & 20 & .438 & .492 \\
\hline Commitment & 20 & .423 & .472 \\
\hline Deliberation & 20 & .395 & .461 \\
\hline \multicolumn{4}{|l|}{ Cross-Dimensions } \\
\hline Personal Aptitude & 5 & .521 & .476 \\
\hline Personal Orderliness & 5 & .442 & .516 \\
\hline Personal Commitment & 5 & .416 & .455 \\
\hline Personal Deliberation & 5 & .505 & .501 \\
\hline Individual Aptitude & 5 & .544 & .612 \\
\hline Individual Orderliness & 5 & .397 & .414 \\
\hline Individual Commitment & 5 & .318 & .348 \\
\hline Individual Deliberation & 5 & .069 & .087 \\
\hline Professional Aptitude & 5 & .463 & .518 \\
\hline Professional Orderliness & 5 & .220 & .311 \\
\hline Professional Commitment & 5 & .247 & .352 \\
\hline Professional Deliberation & 5 & .231 & .335 \\
\hline Relational Aptitude & 5 & .381 & .383 \\
\hline Relational Orderliness & 5 & .350 & .345 \\
\hline Relational Commitment & 5 & .400 & .395 \\
\hline Relational Deliberation & 5 & .408 & .482 \\
\hline Conscientiousness & 80 & .497 & .549 \\
\hline
\end{tabular}

APD $=$ Average Proportional Distance

$\mathrm{XC}=$ Cross-Dimensional Conscientiousness Scale

IPIP NEO = International Personality Item Pool Representation of the NEO PI-R

$\mathrm{BFI}=$ Big Five Inventory

${ }^{\text {a }}$ Conscientiousness scale only

$\mathrm{n}=304$ 
Appendix F.

List of Cross-Dimensional Conscientiousness Scale Item Validity

\begin{tabular}{|c|c|c|c|c|c|}
\hline \multirow[t]{2}{*}{ Item code } & \multirow[t]{2}{*}{ Item key } & \multicolumn{4}{|c|}{ Item-total correlation } \\
\hline & & $\begin{array}{l}\text { Social } \\
\text { Dimension }\end{array}$ & $\begin{array}{l}\text { Trait } \\
\text { Component }\end{array}$ & $\begin{array}{l}\text { Cross- } \\
\text { Dimension }\end{array}$ & $\begin{array}{l}\text { Whole } \\
\text { test }\end{array}$ \\
\hline Personal Aptitude \#1 & Positive & 0.42 & 0.36 & 0.26 & 0.39 \\
\hline Personal Aptitude \#2 & Positive & 0.23 & 0.29 & 0.14 & 0.26 \\
\hline Personal Aptitude \#3 & Positive & 0.38 & 0.37 & 0.32 & 0.38 \\
\hline Personal Aptitude \#4 & Positive & 0.51 & 0.49 & 0.44 & 0.48 \\
\hline Personal Aptitude \#5 & Positive & 0.46 & 0.49 & 0.31 & 0.49 \\
\hline Personal Orderliness \#1 & Positive & 0.51 & 0.55 & 0.38 & 0.56 \\
\hline Personal Orderliness \#2 & Positive & 0.55 & 0.52 & 0.44 & 0.55 \\
\hline Personal Orderliness \#3 & Positive & 0.37 & 0.30 & 0.34 & 0.39 \\
\hline Personal Orderliness \#4 & Positive & 0.49 & 0.44 & 0.35 & 0.54 \\
\hline Personal Orderliness \#5 & Positive & 0.31 & 0.29 & 0.23 & 0.33 \\
\hline Personal Commitment \#1 & Positive & 0.38 & 0.37 & 0.21 & 0.40 \\
\hline Personal Commitment \#2 & Positive & 0.61 & 0.57 & 0.44 & 0.64 \\
\hline Personal Commitment \#3 & Positive & 0.36 & 0.42 & 0.32 & 0.43 \\
\hline Personal Commitment \#4 & Positive & 0.46 & 0.37 & 0.29 & 0.44 \\
\hline Personal Commitment \#5 & Positive & 0.27 & 0.33 & 0.19 & 0.36 \\
\hline Personal Deliberation \#1 & Positive & 0.51 & 0.40 & 0.38 & 0.53 \\
\hline Personal Deliberation \#2 & Positive & 0.49 & 0.47 & 0.41 & 0.50 \\
\hline Personal Deliberation \#3 & Positive & 0.39 & 0.39 & 0.34 & 0.41 \\
\hline Personal Deliberation \#4 & Positive & 0.38 & 0.35 & 0.32 & 0.45 \\
\hline Personal Deliberation \#5 & Positive & 0.50 & 0.43 & 0.38 & 0.48 \\
\hline Individual Aptitude \#1 & Positive & 0.58 & 0.62 & 0.60 & 0.60 \\
\hline Individual Aptitude \#2 & Positive & 0.53 & 0.59 & 0.57 & 0.58 \\
\hline Individual Aptitude \#3 & Positive & 0.56 & 0.58 & 0.55 & 0.60 \\
\hline Individual Aptitude \#4 & Positive & 0.54 & 0.52 & 0.52 & 0.54 \\
\hline Individual Aptitude \#5 & Positive & 0.64 & 0.60 & 0.57 & 0.63 \\
\hline Individual Orderliness \#1 & Positive & 0.59 & 0.53 & 0.47 & 0.57 \\
\hline Individual Orderliness \#2 & Positive & 0.53 & 0.55 & 0.51 & 0.54 \\
\hline Individual Orderliness \#3 & Positive & -0.15 & -0.12 & -0.25 & -0.11 \\
\hline Individual Orderliness \#4 & Positive & 0.35 & 0.30 & 0.22 & 0.36 \\
\hline Individual Orderliness \#5 & Positive & 0.59 & 0.59 & 0.40 & 0.62 \\
\hline Individual Commitment \#1 & Negative & 0.60 & 0.53 & 0.44 & 0.62 \\
\hline Individual Commitment \#2 & Positive & 0.56 & 0.48 & 0.33 & 0.56 \\
\hline Individual Commitment \#3 & Negative & 0.02 & -0.03 & -0.04 & -0.02 \\
\hline Individual Commitment \#4 & Negative & 0.52 & 0.55 & 0.42 & 0.58 \\
\hline Individual Commitment \#5 & Negative & 0.47 & 0.50 & 0.40 & 0.50 \\
\hline Individual Deliberation \#1 & Positive & 0.49 & 0.47 & 0.16 & 0.54 \\
\hline Individual Deliberation \#2 & Positive & -0.12 & -0.02 & 0.07 & -0.06 \\
\hline Individual Deliberation \#3 & Positive & 0.56 & 0.53 & 0.16 & 0.59 \\
\hline Individual Deliberation \#4 & Positive & 0.02 & -0.02 & 0.05 & 0.00 \\
\hline
\end{tabular}




\begin{tabular}{|c|c|c|c|c|c|}
\hline Individual Deliberation \#5 & Positive & 0.45 & 0.47 & 0.23 & 0.50 \\
\hline Professional Aptitude \#1 & Positive & 0.47 & 0.44 & 0.45 & 0.47 \\
\hline Professional Aptitude \#2 & Positive & 0.43 & 0.35 & 0.31 & 0.44 \\
\hline Professional Aptitude \#3 & Positive & 0.62 & 0.56 & 0.49 & 0.61 \\
\hline Professional Aptitude \#4 & Positive & 0.40 & 0.48 & 0.31 & 0.48 \\
\hline Professional Aptitude \#5 & Positive & 0.40 & 0.50 & 0.35 & 0.52 \\
\hline Professional Orderliness \#1 & Positive & 0.57 & 0.56 & 0.36 & 0.62 \\
\hline Professional Orderliness \#2 & Positive & 0.45 & 0.44 & 0.21 & 0.49 \\
\hline Professional Orderliness \#3 & Positive & -0.08 & -0.05 & -0.03 & -0.08 \\
\hline Professional Orderliness \#4 & Positive & 0.16 & 0.16 & 0.18 & 0.12 \\
\hline Professional Orderliness \#5 & Positive & 0.60 & 0.66 & 0.40 & 0.67 \\
\hline Professional Commitment \#1 & Negative & 0.27 & 0.31 & 0.14 & 0.33 \\
\hline Professional Commitment \#2 & Negative & 0.49 & 0.57 & 0.29 & 0.59 \\
\hline Professional Commitment \#3 & Negative & 0.17 & 0.04 & -0.04 & 0.08 \\
\hline Professional Commitment \#4 & Positive & 0.15 & 0.20 & 0.05 & 0.22 \\
\hline Professional Commitment \#5 & Negative & 0.61 & 0.43 & 0.29 & 0.52 \\
\hline Professional Deliberation \#1 & Positive & 0.32 & 0.33 & 0.14 & 0.41 \\
\hline Professional Deliberation \#2 & Positive & 0.10 & 0.07 & 0.07 & 0.02 \\
\hline Professional Deliberation \#3 & Positive & 0.67 & 0.60 & 0.64 & 0.56 \\
\hline Professional Deliberation \#4 & Positive & 0.44 & 0.44 & 0.36 & 0.46 \\
\hline Professional Deliberation \#5 & Positive & 0.62 & 0.56 & 0.58 & 0.53 \\
\hline Relational Aptitude \#1 & Positive & 0.42 & 0.38 & 0.26 & 0.38 \\
\hline Relational Aptitude \#2 & Positive & 0.43 & 0.35 & 0.26 & 0.40 \\
\hline Relational Aptitude \#3 & Positive & 0.32 & 0.29 & 0.15 & 0.37 \\
\hline Relational Aptitude \#4 & Positive & 0.28 & 0.27 & 0.20 & 0.30 \\
\hline Relational Aptitude \#5 & Positive & 0.36 & 0.43 & 0.25 & 0.41 \\
\hline Relational Orderliness \#1 & Positive & 0.44 & 0.46 & 0.30 & 0.52 \\
\hline Relational Orderliness \#2 & Positive & 0.42 & 0.41 & 0.28 & 0.41 \\
\hline Relational Orderliness \#3 & Positive & 0.50 & 0.47 & 0.37 & 0.53 \\
\hline Relational Orderliness \#4 & Positive & 0.38 & 0.32 & 0.34 & 0.41 \\
\hline Relational Orderliness \#5 & Positive & 0.46 & 0.43 & 0.44 & 0.47 \\
\hline Relational Commitment \#1 & Positive & 0.47 & 0.50 & 0.43 & 0.50 \\
\hline Relational Commitment \#2 & Positive & 0.40 & 0.42 & 0.24 & 0.45 \\
\hline Relational Commitment \#3 & Positive & 0.37 & 0.35 & 0.26 & 0.38 \\
\hline Relational Commitment \#4 & Positive & 0.53 & 0.54 & 0.47 & 0.59 \\
\hline Relational Commitment \#5 & Positive & 0.40 & 0.35 & 0.25 & 0.41 \\
\hline Relational Deliberation \#1 & Positive & 0.55 & 0.54 & 0.49 & 0.58 \\
\hline Relational Deliberation \#2 & Positive & 0.46 & 0.46 & 0.33 & 0.49 \\
\hline Relational Deliberation \#3 & Positive & 0.23 & 0.27 & 0.21 & 0.28 \\
\hline Relational Deliberation \#4 & Positive & 0.54 & 0.55 & 0.53 & 0.56 \\
\hline Relational Deliberation \#5 & Positive & 0.44 & 0.39 & 0.32 & 0.49 \\
\hline
\end{tabular}

